\title{
O QUE O BRASIL APRENDEU COM A PANDEMIA DE 2020?
}

\author{
WHAT DID BRAZIL LEARN FROM THE PANDEMIC IN 2020?
}

\author{
Rogério Makino ${ }^{1}$ \\ Hérica Makino ${ }^{2}$
}

Recebido: 10/10/2020

Aceito: $23 / 12 / 2020$

Resumo: Nesse texto, esboça-se uma interpretação sobre como o Brasil lidou com a pandemia de Covid-19 e um cenário hipotético sobre como será o país pós-pandemia. Argumenta-se que eventos traumáticos em grande escala são oportunidades de aprendizagem social, mas que, no caso brasileiro, houve uma conjunção de fatores culturais, políticos e ideológicos que bloqueou essa oportunidade. A reflexividade - conceito tão alardeado sobre a modernidade - não parece ser a protagonista dessa conjuntura. Entre os fatores mencionados, entrelaçam-se e retroalimentam-se o anti-intelectualismo, o relativismo e o negacionismo, consonantes com o discurso oficial governamental, e potencializados por elementos socioculturais brasileiros como um individualismo exacerbado e a pouca responsabilidade para com o coletivo. Ao final, são listadas algumas lições que deveriam, mas provavelmente não serão aprendidas pelo Brasil.

Palavras-chave: Pandemia; Covid-19; Brasil; Negacionismo; Reflexividade.

Abstract: In this text, the authors sketch an interpretation about how Brazil dialed with the Covid-19 and a hypothetical scenario about the future of the country after the pandemic. Large-scale traumatic advents era opportunities of social learning, but in the Brazilian case, there was a convergence of cultural, political and ideological factors, which has blocked it. The reflexivity - famous concept about modernity - does not seem to be present completely in this conjuncture. Among those factors, anti-intelctualism, relativism, and denialism reinforce each other, aligned with the official government speech, and magnified by some Brazilian sociocultural features such as intense individualism and low responsibility with collective rights. By the end, some lections suggested are, but probably they be will not learned.

Keywords: Pandemic; Covid-19; Brazil; Denialism; Reflexivity.

\footnotetext{
${ }^{1}$ Doutor em Ciências Sociais pela Universidade de Brasília (UnB). Professor na Universidade do Estado de Mato Grosso (UNEMAT), Tangará da Serra - MT. E-mail: makinotga@gmail.com

${ }^{2}$ Mestre em Ciências Veterinárias pela Universidade Federal de Mato Grosso (UFMT). Técnica Administrativa na UFMT, Doutoranda em Ciências Veterinárias pela UFMT, campus de Cuiabá. E-mail: hericamak@yahoo.com.br
} 


\section{Introdução}

Alguns episódios traumáticos podem causar mudanças culturais, políticas, sociais e econômicas, como crises econômicas agudas, guerras ou epidemias devastadoras. As mudanças podem ser estruturais - profundas e com efeitos de longo prazo - ou podem ser conjunturais - mais superficiais e passageiras. O tipo de mudança geralmente depende da gravidade do trauma produzido.

Eventos como a Primeira Guerra Mundial, a Segunda Guerra Mundial e a Crise de 1929, por exemplo, desencadearam mudanças estruturais nos valores, nos padrões de comportamento e nas instituições econômicas e políticas. Para que as mudanças ocorram, é necessário haver um aprendizado social a partir dos eventos traumáticos, o que pressupõe que as pessoas sejam adequadamente informadas e estejam abertas a repensarem suas convicções, mas nem sempre isso ocorre.

Nesse ensaio, de caráter crítico, argumenta-se que a pandemia de Covid-19 é um evento traumático quando se pensa no seu grande saldo de vítimas, mas que há fatores presentes no Brasil que dificultam uma aprendizagem social e, consequentemente, mudanças estruturais e, talvez, mesmo conjunturais. Entre esses fatores há uma pouca vontade de se entender o que são direitos individuais e seus limites, pouca valorização do conhecimento e da reflexão e o contexto político atual.

\section{Liberdade Individual e Segurança Coletiva}

As sociedades ocidentais contemporâneas, autodenominadas civilizadas, tentaram equilibrar as liberdades individuais e a segurança coletiva. Os arranjos políticos que privilegiam a segurança coletiva ou fazem uso dela discursivamente tentam minar as liberdades individuais e a democracia. Já uma postura em que a liberdade individual é levada às últimas consequências resultaria na anarquia, na selvageria e no caos, na qual inclusive colocaria em risco a existência de todos. Para que isso fique mais claro, faça uma experiência mental: se todas as pessoas tivessem a liberdade de construir a sua própria bomba atômica, quanto tempo duraria a humanidade? O famoso sociólogo e filósofo polonês Zygmunt Bauman (2017) resume esse dilema na ideia de que segurança sem liberdade é opressão, mas liberdade sem segurança é caos.

Esse equilíbrio é o tempo todo tensionado por ideologias que acentuam um lado ou outro. No contexto brasileiro, os interesses econômicos aliados a uma má vontade de se 
compreender o que é democracia, liberalismo e cidadania dificultam um debate civilizado sobre direitos e liberdades individuais. Veja-se, por exemplo, o conceito de cidadania que carrega uma longa história de lutas para que o Estado reconhecesse direitos civis, políticos e sociais. Ser cidadão é ter a possibilidade de exercer direitos reconhecidos pelo Estado, um privilégio restrito a poucos no passado. A contrapartida pelo reconhecimento de direitos por parte do Estado é o reconhecimento por parte do cidadão que ele próprio tem deveres para com o Estado e com os seus concidadãos. É difícil desassociar direitos e deveres da mesma forma que é difícil desassociar liberdade e responsabilidade. No entanto, no Brasil, não incomum por parte de uma grande parcela da sociedade o esquecimento proposital dos deveres em concomitância com uma tentativa de tornar os seus direitos ilimitados. Para ela, "cidadão" é ofensa, a responsabilidade é apenas dos outros e isonomia é um atentado subversivo à ordem nacional.

Um dos capítulos da história brasileira que pode ser ilustrativo, nesse sentido, é sobre os políticos liberais escravocratas do século XIX. Diziam-se adeptos de uma filosofia que prega que a liberdade é o principal valor humano a ser defendido, mas eram contra a abolição da escravatura (GORENDER, 2002). Talvez, um pouco dessa flexibilidade discursiva sobrevive na elite brasileira e naqueles que pensam que fazem parte da elite brasileira, reformulando os discursos para tentar justificar o abismo entre crenças declaradas e ações praticadas. No fundo, são os interesses imediatistas e egoístas que condicionam essas pessoas; as justificativas vêm a posteriori e moldam-se aos interesses.

Nesse contexto, a segurança coletiva ou a responsabilidade social, quando contraria esses interesses, é identificada como valores do inimigo que devem ser combatidos, genericamente rotulados de "papo de comunista", "globalismo", "marxismo cultural", etc. Essa identificação da segurança coletiva como algo ligado ao adversário político dificulta a elaboração de políticas públicas, o que tem se refletido no combate à pandemia e na conscientização das pessoas. Ao fim, reivindica-se uma liberdade individual ilimitada que ameace a liberdade e a vida dos outros, de modo que qualquer justificativa serve.

\section{Lugar de fala e de morte e naturalização do absurdo}

O impacto da morte de uma pessoa é análogo, em certa medida, ao lugar de fala de uma pessoa: da mesma que nem todas as pessoas que falam são ouvidas, nem todas as mortes são lamentadas com o mesmo pesar. Em uma sociedade racista, a morte de um negro é menos 
lamentada do que a morte de um branco. Em uma sociedade classista, a morte de um pobre é menos sentida pelos policy-makers do que a de um rico. Em uma sociedade que não valoriza seus idosos, essas vidas são encaradas como um fardo descartável. Dito de outra forma, 150 mil mortes $^{3}$ de pessoas negras, pobres e idosas não causam a mesma comoção nacional que causaria a morte de 150 mil jovens brancos de classe média alta. Em nível de Brasil, as mortes por Covid-19 estão concentradas justamente nesses grupos: negros, pobres e idosos.

Os grupos mais econômica e politicamente empoderados no Brasil têm pouca empatia pelo perfil daqueles que estão morrendo. A fome, a miséria, as longas filas do SUS e a truculência da polícia na periferia nunca foi um incômodo para eles: incomodaria muito mais um projeto de reforma de bases, como a proposta pela presidente João Goulart em 1963 ou uma proposta de imposto sobre grandes heranças, lucros e dividendos. As mortes de idosos, pobres e negros são encaradas como um preço justo a ser pago para que os lucros do topo da pirâmide social não sejam temporariamente suspensos. Essa própria elite sente-se invulnerável à doença porque foi criada em cultura que a faz sentir acima das regras e das leis. Ela pensa que as leis da infectologia e da epidemiologia seguem a mesma lógica do Estado de Direito brasileiro a quem se pode dizer: "você sabe com quem está falando?”.

Um absurdo quando se estende por períodos temporais longos tende a ser naturalizado. As pessoas ficam chocadas quando não havia mortes por uma doença e, de repente, começa a haver. Mas se essas mortes começam a ocorrer todos os dias, isso começa a ser naturalizado e acaba se tornando "normal". Não choca. E se os aumentos no número de mortes forem graduais, o "novo normal” pode ser muito alto. É isso que está acontecendo no Brasil: mil mortes de Covid-19 por dia foram naturalizadas.

Mesmo o esforço dos Grupos Globo de comunicação, um dos maiores conglomerados do tipo no Brasil, em apelar para o lado emocional das pessoas e tentar chocá-las expondo o tamanho da tragédia diariamente não está surtindo efeito. Se, no passado, a Globo elegia e derrubava presidentes, como aconteceu com o presidente Collor (IBARGOYEN, 2019), a pandemia de Coronavírus deixou claro que sua hegemonia sobre

\footnotetext{
${ }^{3}$ Um dos cenários previstos pelo Instituto para a Métrica e a Avaliação da Saúde em agosto de 2020 para o mês de novembro de 2020 .

${ }^{4} \mathrm{O}$ antropólogo Roberto DaMatta, em seu livro "Carnavais, Malandros e Heróis", destaca que a isonomia (igualdade perante a lei) não é um valor da cultura brasileira, por isso frases como "você sabe com quem está falando?" é tão corriqueira.
} 
as narrativas e o seu semimonopólio sobre as informações esfacelaram-se em tempos de internet.

\section{Relativismo, negacionismo e anti-intelectualismo}

No passado, os iluministas acreditavam que as mazelas da humanidade tinham a ver com a falta de acesso a informação e, por isso, alguns deles se puseram em empreitadas como a elaboração da enciclopédia. No entanto, o advento da internet - que ampliou o acesso à informação - deixou claro que o problema não era apenas esse.

A maior parte das mazelas da humanidade é, para usar uma expressão que se tornou lugar comum, socialmente construída. Não quero dizer que o vírus Sar-Cov-2 não é uma construção social, mas sim as estruturas que facilitam sua disseminação em nível global e potencializam o número de mortos. De um ponto de vista otimista, em tese, tudo que é socialmente construído pode ser socialmente desconstruído e reconstruído. De um ponto de vista pessimista, o fato de algo ser uma construção social não quer dizer que seja fácil de ser mudado. Para que haja uma maior probabilidade de mudanças, vários elementos devem ser levados em conta.

Em primeiro lugar, a internet permitiu um volume gigantesco de informação circulasse e estivesse acessível instantaneamente a um grande número de pessoas. Mas, no que circula nas redes, há muitas informações que são inverídicas, apresentadas de forma parcial ou seletiva e direcionadas para públicos específicos. Há uma verdadeira guerra de informação e desinformação no mundo virtual. Todo o debate sobre as fake news e a Cambridge Analytica (direcionamento da desinformação planejado por empresas especializadas para públicos mais suscetíveis) são exemplos dessa guerra. No caso da Covid19, as desinformações sobre o número de mortos e de supostas curas miraculosas como a cloroquina têm uma popularidade muito grande ${ }^{5}$.

Em segundo lugar, o aprendizado depende de duas qualidades cognitivas: (1) que os cidadãos tenham um espírito crítico - capaz de diferenciar informações verdadeiras e falsas bem como os interesses envolvidos; e (2) o que o sociólogo Anthony Giddens (1991) chama de reflexividade - a habilidade cognitiva de reexaminar suas ações e posicionamento a partir de novas informações. Em outras palavras, a pessoa reflexiva muda a sua convicção diante

\footnotetext{
${ }^{5}$ Em pesquisa feita pelo Instituto Ipsos, publicada pela Revista Valor Econômico, em 20 de julho de 2020 , $18 \%$ dos brasileiros entrevistados acreditam que a cloroquina tem potencial de cura para Covid-19.
} 
de novas evidências, enquanto a pessoa não reflexiva relativiza, seleciona os fatos, distorce as informações e nega as evidências para manter a sua convicção. Entretanto, as redes sociais, que tanto caíram no gosto dos brasileiros, parecem favorecer a dimensão emocional e afetiva das pessoas, exacerbando uma postura narcisista de não admitir o erro e de limitar as interações a pessoas que pensam de forma similar, o que diminui o seu espírito crítico e a sua reflexividade.

Em terceiro lugar, mesmo antes de 2018, percebia-se o aumento da presença de posturas relativistas, negacionistas e anti-intelectuais nas redes sociais ou mesmo nas conversas presenciais informais. A rigor, elas sempre existiram de alguma forma ao longo da história humana, mas na modernidade não representavam uma concorrente para a ciência nem ameaçavam a sua legitimidade. Foi a partir da popularização da internet e do empoderamento dos filodoxos digitais nos últimos anos que elas passaram a desafiar a ciência e o bom senso. Mas foi em seu encontro com o bolsonarismo que elas encontraram a oportunidade de se amplificar a partir dos microfones oficiais.

O relativismo pressupõe a coexistência de verdades contraditórias e mutuamente excludentes, o que permite reduzir tudo a opinião. Nessa perspectiva, o posicionamento de um epidemiologista sobre uma pandemia tem o mesmo valor de uma pessoa que não sabe o que é um vírus, fontes de contaminação viral ou noções básicas de assepsia. É uma posição confortável para mentes preguiçosas de uma classe média brasileira que ama diplomas, mas é indiferente ao conhecimento. ${ }^{6}$

O negacionismo é a posição de negar fatos estabelecidos ou conhecimentos amplamente aceitos pelos especialistas de uma área, como pode se observar nos movimentos terraplanistas, antivacina e naqueles que não acreditam nas mudanças climáticas. Para contornar as explicações dos especialistas, é comum que se recorra a teorias conspiratórias, como a de que a cloroquina seja uma cura efetiva e barata para a Covid-19, mas que contrariaria os interesses da indústria farmacêutica, apesar de todas as evidências científicas que sugerem a sua ineficácia.

O anti-intelectualismo é um fenômeno de rejeição aos intelectuais, aos especialistas, aos cientistas e aos profissionais acadêmicos. Pessoalmente, acredito que exista uma

\footnotetext{
${ }^{6}$ Ronie Silveira (2019), em seu livro Filosofia Brasileira, trabalha com a ideia de que existe na brasilidade um sentimento de que o auto aperfeiçoamento é desnecessário. Isso faz com que a cultura brasileira não valorize o conhecimento e a sabedoria que possa implicar em mudanças profundas em seus modos de ser, agir e pensar.
} 
explicação psicanalítica: os anti-intelectuais inconscientemente duvidam de suas habilidades cognitivas, rejeitando aqueles nos quais eles não conseguem se tornar. Retomando o argumento, a postura anti-intelectual tem preferências por simplificações que podem reduzir a binarismos, como bem-mal, amigo-inimigo, céu-inferno, direita-esquerda, nacionalistaantipatriótico, capitalista-comunista, etc.

As posturas relativistas, negacionistas e anti-intelectuais encontraram no bolsonarismo a possibilidade de aumentar o seu alcance, enquanto o bolsonarismo encontrou nessas posturas as fontes de justificativas para si mesmo e as armas para combater seus adversários. Na definição de Pinheiro-Machado \& Freixo (2019), o bolsonarismo é:

(...) entendido como um fenômeno político que transcende a própria figura de Jair Bolsonaro, e que se caracteriza por uma visão de mundo ultraconservadora, que prega o retorno aos valores tradicionais e assume uma retórica nacionalista e patriótica, sendo profundamente crítica a tudo que esteja minimamente identificado com a esquerda e o progressismo. Tal visão de mundo ganhou bastante força nessa última década em várias partes do mundo, se alimentando da crise de representação e da descrença generalizada na política e nos partidos tradicionais.

Não é necessário se prolongar na discussão sobre as origens, as características essenciais e os paralelos do bolsonarismo com outras ondas similares mundo afora, pois há muitos textos que exploram o tema de forma muito mais qualificada ${ }^{7}$. Basta dizer que o bolsonarismo é uma gambiarra ideológica que une interesses de neoliberais poderosos, de classes do aparelho repressivo do Estado, do conservadorismo de grupos religiosos crescentes no país e de outros, cimentados por um antipetismo paranoico - que foi cevado por muito tempo pelos meios de comunicação em massa no Brasil.

O discurso bolsonarista tem um apelo emocional, amparado pelo amplo uso de relativismo, negacionismo e anti-intelectualismo. Seus adeptos mais radicais dificilmente serão convencidos por qualquer coisa que contrarie suas como convicções, mesmo que estejam diante de fatos ou argumentos racionais. Suas convicções passam a seguir uma lógica religiosa impermeável à ciência e ao bom senso ou, em outras palavras, carecem de reflexividade e espírito crítico. Nessas condições, não há aprendizado para esses indivíduos.

\footnotetext{
${ }^{7}$ Alguns livros muito interessantes como Democracia em Risco da Companhia das Letras, O Ódio como Política organizado por Esther Solano e As Direitas na Rede e nas Ruas, organizado por Esther Solano e Camila Rocha.
} 
Em um nível social mais amplo, uma parcela muito grande de indivíduos desse tipo impede a construção de consensos e mudanças estruturais ${ }^{8}$.

Na linguagem técnica da metodologia científica, o bolsonarismo seria uma variável independente, ou seja, o fator que quando presente explica o fenômeno. Os países sem a presença forte de ideologias análogas ao bolsonarismo estão enfrentando a pandemia de outra forma e provavelmente terão um aprendizado social diferenciado, mais profundo e duradouro. Se isso ocorrer mesmo, eles estarão mais preparados para novas pandemias do que estavam para o Coronavírus. Em outros casos, como os Estados Unidos, até há um presidente com características parecidas com o brasileiro, mas a ideologia que o acompanha é menos intensa e a proporção de adeptos radicalizados aparentemente é menor. Isso favorece um aprendizado social que, talvez, já esteja em andamento e manifeste-se na eleição presidencial de novembro de 2020.

\section{E se fôssemos reflexivos e críticos, o que poderia mudar?}

É muito criticado o conceito de Sérgio Buarque de Holanda (2016) de que o brasileiro é o homem cordial (do latim, cordis, que significa coração), alguém que age mais de acordo com o coração do que com a razão. Nessa perspectiva, o convencimento e a persuasão viriam por um apelo emocional e não por um apelo racional, de modo que a coerência argumentativa e as evidências factuais não são elementos decisivos para que um brasileiro adote um tipo de posicionamento. É como se a reflexividade e o espírito crítico, comentados anteriormente, não fossem habilidades cognitivas valorizadas e estimuladas na cultura brasileira de acordo com a teoria da cordialidade.

Novamente, façamos outro experimento mental: se nós - brasileiros - fôssemos um povo crítico, reflexivo e bem informado, que lições deveríamos apreender e que mudanças estruturais poderiam decorrer dessa aprendizagem? Nesse sentido, listo alguns pontos que creio importantes:

1 - Comportamento de higiene: as pessoas deveriam aprender a lavar as mãos (ou usar o álcool gel) com mais frequência, o costume de usar máscaras para se proteger e proteger os outros, como acontece em alguns países no Oriente, novas formas de cumprimentar, evitar aglomerações, etc.

\footnotetext{
${ }^{8}$ De acordo com as pesquisas da XP/Ipespe, as avaliações de bom e ótimo relacionados a Bolsonaro nunca foram inferiores a $25 \%$ até julho de 2020 , geralmente se mantendo acima de $30 \%$.
} 
2 - Sobre a saúde pública: as pessoas deveriam aprender a importância de um sistema universal e público de saúde e passar a encarar o SUS (Sistema Único de Saúde) como um patrimônio do povo brasileiro a ser defendido. Mesmo para aqueles que têm um plano de saúde, em caso de doenças infectocontagiosas, o melhor para diminuir o risco de sua contaminação é que todos, independentemente da classe social, tenham acesso à saúde.

3 - O individualismo levado às últimas consequências é uma ameaça a todos: as liberdades individuais não são ilimitadas, pois, como indivíduos que vivem em sociedade, temos tanto direitos quanto deveres ou, como dizia nossa avó, o meu direito acaba quando começa o do outro. Além disso, é muito complicado achar que liberdade nada tem a ver com responsabilidade. A liberdade individual elevada à enésima potência nada mais é do que uma anarquia caótica que põe em risco a todos nós.

4 - Todos somos iguais na morte, mas alguns são mais iguais do que outros ${ }^{9}$ : o fato de que todos vamos morrer não significa que corremos exatamente os mesmos riscos nem que morreremos sob as mesmas condições e menos ainda que as pessoas se comoverão com a nossa morte da mesma maneira.

5 - Não se refuta ciência e fatos com opinião: há uma profunda confusão entre fato e opinião bem como uma falsa equivalência entre posicionamento com base em conhecimento e posicionamento com base em ignorância. Quando se desprezam os alertas científicos, aumenta-se a probabilidade do número e do tamanho das catástrofes.

6-Não há salvadores da pátria nem soluções simplistas: não adianta esperar por um duce, um Führer ou um messias que com o sacudir de uma varinha de condão resolverá todos os problemas nacionais. Se fossem fáceis de resolver, já teriam sido resolvidos. Quem se apresenta como líder salvacionista não passa de um louco ou de um oportunista demagógico. É preciso ter a responsabilidade cidadã de não se deixar enganar por esses personagens, manter o espírito crítico e fiscalizador das ações dos nossos líderes e não ser reduzidos a puxa-sacos de políticos.

7 - O respeito ao meio ambiente deve ser levado a sério: as áreas nativas preservadas abrigam uma grande diversidade de micro-organismos, muitos dos quais ainda desconhecidos pela ciência e potencialmente perigosos para os humanos. A exploração

9Uma referência à frase de George Orwell no livro "A Revolução dos Bichos". 
predatória e descontrolada dessas áreas permite o contato com esses patógenos e pode ser uma fonte para novas pandemias.

8 - O Estado mínimo serve ao interesse de um número mínimo de pessoas, as quais já possuem o máximo: as forças dos mercados deixadas por si só não resolvem problemas de equidade, não promovem justiça social e não protegem os direitos da coletividade. Não é no Brasil, uma das sociedades mais desiguais (com riqueza concentrada) do mundo, que a maior parte das pessoas terá acesso a serviços essenciais como saúde, educação e seguridade social sem a atuação estatal.

9 - Cooperação Internacional: não vivemos em uma ilha isolada e autônoma do resto do mundo. Não produzimos insumos hospitalares, remédios e tecnologias sanitárias capazes de suprir nossas necessidades nem em tempos normais, menos ainda em tempos de pandemia. A construção de acordos e projetos de cooperação internacional com outros países pode mutuamente benéfico e ajudar em situações como essa.

\section{Considerações finais}

Dizem que o ideograma para o termo "crise" em língua chinesa é composto dos caracteres para "perigo" e “oportunidade". É interessante pensar que algumas crises oferecem oportunidades para aprender, mudar e melhorar. Mas quando essa oportunidade é desperdiçada, incorre-se no perigo de cometer os mesmos erros em novas crises parecidas.

Nesse ensaio, argumentou-se que a blindagem ideológica do bolsonarismo é o fator que impede o aprendizado social a partir da pandemia que assola o Brasil. O bolsonarismo fortaleceu-se em sua simbiose com o relativismo, o negacionismo e anti-intelectualismo. Se estiverem corretas as teorias que apontam para uma menor reflexividade da sociedade brasileira, esse pode ser o fator que intensifica o poder de blindagem do bolsonarismo.

Várias lições poderiam ser aprendidas com o trágico episódio do Coronavírus. Em alguns países, com uma noção de cidadania mais esclarecida - com os direitos individuais dentro dos limites civilizados e equilibrados com os deveres - e sem uma blindagem ideológica que sufoque a reflexidade é provável que ocorram algumas mudanças. No Brasil, algumas pessoas aprenderão algo, mas não aquelas que estão mais bem posicionadas politicamente para fazer algo pelo coletivo, talvez porque os seus valores não contemplem a segurança coletiva, o conhecimento científico, o bom senso e empatia. 


\section{Referências}

ABRANCHES, Sérgio et al. Democracia em Risco: 22 ensaios sobre o Brasil hoje. $1^{\text {a }}$ ed. Companhia das Letras, 2019.

BAUMAN, Zygmunt; DESSAL, Gustavo. O Retorno do Pêndulo: sobre a psicanálise e o futuro do mundo líquido. Editora Schwarcz-Companhia das Letras, 2017.

BRYM, Robert J. et al. Sociologia: uma bússola para um novo mundo. Cengage Learning, 2006.

GIDDENS, Anthony. As Consequências da Modernidade. São Paulo: Editora UNESP, 1991.

GORENDER, Jacob. Liberalismo e Escravidão. Entrevista. Estudos Avançados, 2002.

HOLANDA, Sérgio Buarque de. As Raízes do Brasil. Edição Crítica. Companhia das Letras, 2016.

IBARGOYEN, Loiret Chiappa. O Fenômeno Collor: quando a mídia transforma um “cassador” em cassado (1988 - 1992). TCC (Graduação em História). Universidade Federal do Rio Grande do Sul. Porto Alegre - RS, 2019.

LIMA, Leila Souza. $18 \%$ dos brasileiros veem cloroquina como curda da Covid; $7 \%$ creem no alho. Valor Econômico. São Paulo, 20 de julho de 2020.

MATTA, Roberto da. Carnavais, Malandros e Heróis: para uma sociologia do dilema brasileiro. Rio de Janeiro: Rocco, 1979.

ORWELL, George. A Revolução dos Bichos. Companhia das Letras, 2007.

PINHEIRO-MACHADO, Rosana; FREIXO, Adriano de. Brasil em Transe:

bolsonarismo, nova direita e desdemocratização. Rio de Janeiro: Oficina Raquel, 2019.

SILVEIRA, Ronie A. T. Filosofia Brasileira. Porto Alegre: Editora Fi, 2019.

SOLANO, Esther; ROCHA, Camila (Orgs). As Direitas na Rede e nas Ruas: a crise política no Brasil. São Paulo: Expressão Popular, 2019.

SOLANO, Esther (org). O Ódio como Política: a reinvenção das direitas no Brasil. Boitempo Editorial, 2018. 